\title{
Adsorption of Plasma Proteins on Arg-Gly-Asp-Ser Peptide-Immobilized Poly(vinyl alcohol) and Ethylene-Acrylic Acid Copolymer Films
}

\author{
Kensuke NaKaJima, Yoshiaki Hirano, Takeo IIDA, \\ and Akio NAKaJIMA* \\ Department of Applied Chemistry, Osaka Institute of Technology, \\ 5-16-1 Ohmiya, Asahi-ku, Osaka 535, Japan
}

(Received May 1, 1990)

\begin{abstract}
Tetrapeptide Arg-Gly-Asp-Ser (RGDS) exhibiting cell-attachment activity was immobilized to poly(vinyl alcohol) (PVA), and to ethylene-acrylic acid copolymer (PEA) conaining $2.84 \mathrm{~mol} \%$ acrylic acid. RGDS was also immobilized to PEA via Gly-Gly-Gly (GGG) as a spacer. Adsorption behaviors of plasma proteins, albumin and $\gamma$-globulin, on these peptide-immobilized PVA and PEA surfaces were examined in phosphate buffer solution by means of interfacial pressure. It was found that the interfacial pressures of these polymer surfaces were drastically lowered by immobilizing the peptides, RGDS and GGGRGDS.
\end{abstract}

KEY WORDS Plasma Proteins Adsorption / Arg-Gly-Asp-Ser (RGDS) peptide / RGDS-Immobilized Polymer Film / Surface Pressure / Surface Area / Interfacial Pressure / Ethylene-Acrylic Acid Copolymer / Poly(vinyl alcohol) /

Along with the recent progress in structure elucidation on cell-adhesive proteins such as fibronectin, vitronectin, and laminin, some specified amino acid sequences in these proteins were presumed to act as the cell-attachment determinant of the proteins. An amino acid sequence, -Arg-Gly-Asp-Ser- (-RGDS-), is said to afford the cell-attachment site of fibronectin which locates in the blood plasma and on the cell surface. Piershbacher and co-workers ${ }^{1,2}$ have pointed out that synthetic tetrapeptide Arg-Gly-Asp-Ser (RGDS) exhibits cell-attachment activity. In a separate paper, ${ }^{3}$ authors examined the cell-attachment activity toward RGDS-immobilized poly(vinyl alcohol) film by using L-929 cells. The aim of this paper is to discuss adsorption of plasma proteins represented by albumin and $\gamma$-globulin onto RGDS-immobilized polymer films, be- cause, in the application of materials exhibiting cell-attachment activity, for example, as a cell cultivation substrate, cell cultures are carried out in the presence of serum.

In this paper, RGDS was immobilized to poly(vinyl alcohol) (PVA) and to ethyleneacrylic acid $(2.84 \mathrm{~mol} \%)$ copolymer (PEA) films. Besides, Gly-Gly-Gly-Arg-Gly-AspSer (GGGRGDS) peptide immobilized to PEA film was also examined to investigate the effect of GGG sequence introduced as a spacer. The protein adsorption behaviors were examined after the procedures and theoretical treatments reported earlier by us. ${ }^{4}$

\section{EXPERIMENTAL}

\section{Materials}

The protein samples used for adsorption

\footnotetext{
* To whom all correspondence should be addressed.
} 
were bovine serum albumin (BSA) and bovine serum $\gamma$-globulin (IgG), both purchased from Sigma. These proteins were dissolved in a phosphate buffer solution (PBS) composed of $\mathrm{Na}_{2} \mathrm{HPO}_{4}, \mathrm{NaH}_{2} \mathrm{PO}_{4}$, and water $(\mathrm{pH}=7.4)$.

The polymers used for immobilization of oligopeptides were poly(vinyl alcohol) (PVA) purchased from Aicello Chemical Inc., and ethylene-acrylic acid (acrylic acid content, $2.84 \mathrm{~mol} \%$ ) copolymer (PEA) contributed from Teijino Co., Ltd. PVA and PEA films were prepared by casting from $5 \mathrm{wt} \%$ dimethyl sulfoxide solution and from $2 \mathrm{wt} \%$ cyclohexane-dioxane $(8: 2, \mathrm{v} / \mathrm{v})$ solution, respectively, on glass plates $(38 \times 13 \times 1 \mathrm{~mm})$. Finally films were dried in vacuo for 5 days at $40^{\circ} \mathrm{C}$. Oligopeptides RGDS and GGGRGDS used were synthesized by liquid-phase procedure. $^{5}$ Immobilization on of oligopeptides is as follows.

\section{Immobilization of Oligopeptides}

In a glass vessel, $2 \mathrm{~g} p$-toluene sulfonyl chloride was dissolved in $7 \mathrm{ml}$ diethylether, to which two PVA films were introduced and allowed to stand for $2 \mathrm{~h}$ at $20^{\circ} \mathrm{C}$. Whereby, $\mathrm{OH}$ residues locating on the film surface were activated. Then, $80 \mathrm{mg}$ RGDS peptide was reacted with the activated PVA films for $72 \mathrm{~h}$ at $30^{\circ} \mathrm{C}$ in phosphate buffer solution adjusted to $\mathrm{pH} 4.5$, filled in a glass vessel. Thus, the RGDS peptide was immobilized to PVA film at its $\mathrm{N}$-terminal.

Immobilizations of RGDS and GGGRGDS peptides to PEA were performed as follows. The $-\mathrm{COOH}$ residues locating on the PEA film surface were activated at $0^{\circ} \mathrm{C}$ for $30 \mathrm{~min}$ with $4 \mathrm{~g}$ water-soluble carbodiimide dissolved in $400 \mathrm{ml}$ phosphate buffer solution ( $\mathrm{pH} 4.5$ ). Then $80 \mathrm{mg}$ RGDS peptide was reacted with the activated PEA film for $4 \mathrm{~h}$ at $0^{\circ} \mathrm{C}$. Thus, the RGDS peptide was immobilized to PEA film at its $\mathrm{N}$-terminal. The immobilized film was rinsed with pure water for $72 \mathrm{~h}$, and then dried in vacuo for 4 days. With respect to GGGRGDS peptide, the same procedures were carried out to immobilize the peptide.

Surface characterization of immobilized films was carried out by means of $\mathrm{C} 1 \mathrm{~s}$ and N1s spectra measured with a Shimadzu 750 ESCA spectrometer using $\mathrm{Mg} K_{\alpha 1,2}$ exciting radiation.

\section{Procedures to Determine Surface Pressure and}

Surface Area of Adsorbed Proteins, and Critical Surface Tension of Films

Adsorption kinetics of protein on polymer film surface in phosphate buffer solution (PBS) was quantitatively described elsewhere, ${ }^{4}$ i.e., the surface pressure $\Pi$ is related to the surface area $A$ of the adsorbed protein by:

$$
\begin{aligned}
& \quad \frac{\mathrm{d} \Pi}{\mathrm{d} t}=k_{1}\left\{c_{0}\left(\frac{\mathrm{d} \Gamma}{\mathrm{d} \Pi}\right)^{-1}-\frac{1}{\sqrt{\pi D}} \int_{0}^{t} \frac{\Pi^{\prime}(\tau)}{\sqrt{t-\tau}} \mathrm{d} \tau\right\} \\
& \times \exp \left(-\frac{\Pi A}{k T}\right)-k_{2} \Pi
\end{aligned}
$$

where $\Gamma$ is the number of protein molecules adsorbed per unit area, $t$ is the time, $\Pi^{\prime}=\Pi / d t$, $D$ is the diffusion constant of protein, $C_{0}$ is the bulk concentration of protein, $k_{1}$ and $k_{2}$ are the rate constants for adsorption and desorption, respectively, and $k$ is the Boltzman constant. If the desorption constant $k_{2}$ is assumed to be 0 , then $A$ is estimated from $\log (\mathrm{d} \Pi / d t)$ vs. $\Pi$ curve.

The surface pressure $\Pi$, as a function of time, was determined from measurements on contact angles developed by us, ${ }^{4}$ and the interfacial tensions by Wilhelmy Plate method. The contact angles, $\theta^{\prime}(t)$, of protein solution and $\theta$ of reference solution (PBS) on polymer film surface were measured in $n$-hexane. The equation ${ }^{4}$ used is;

$$
\Pi=\gamma_{\mathrm{HW}}^{\prime}(t) \cos \theta^{\prime}(t)-\gamma_{\mathrm{HW}} \cos \theta
$$

where, $\gamma_{\text {HW }}$ is the interfacial tension between $n$-hexane $(H)$ and reference solution $(W)$, and $\gamma_{\mathrm{HW}}^{\prime}(t)$ is that between $n$-hexane and protein solution $\left(W^{\prime}\right) . \Pi, \gamma_{\mathrm{HW}}^{\prime}(t)$ and $\cos \theta^{\prime}(t)$ depend on time, but $\gamma_{\mathrm{HW}}$ and $\cos \theta$ are independent of time. Protein solutions used were $0.1 \mathrm{wt} \%$ BSA 
and $0.1 \mathrm{wt} \%$ IgG solutions dissolved in PBS throughout the experiment.

The critical surface tensions $\gamma_{c}$ of films used were derermined from Zisman plots ${ }^{6}$ by using 10 liquids of surface tensions covering 36.23 to $72.30 \mathrm{dyn}^{-1}$.

\section{RESULTS AND DISCUSSION}

\section{Characterization of Oligopeptide-Immobilized} Polymer Surface

Figures 1 and 2 illustrate $\mathrm{C} 1 \mathrm{~s}$ and N1s ESCA spectra for PVA and RGDS-PVA, respectively. Figures 3 and 4 are those for PEA, RGDS-PEA, and GGGRGDS-PEA. The numerical ESCA data are tabulated together with the critical surface tension $\gamma_{c}$ of the films in Table I.

Oxygen to carbon ratio $(\mathrm{O} / \mathrm{C}$ ratio) in $\%$ unit of bulk PVA is 50 . The obtained value

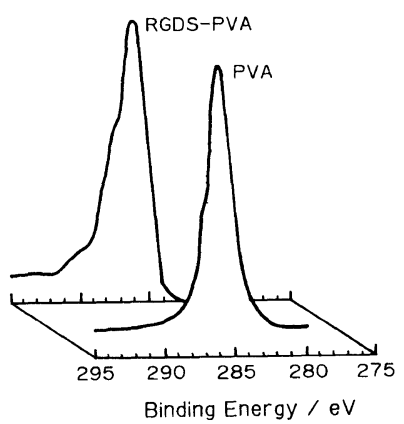

Figure 1. C1s ESCA spectra of PVA and RGDS-PVA surfaces.

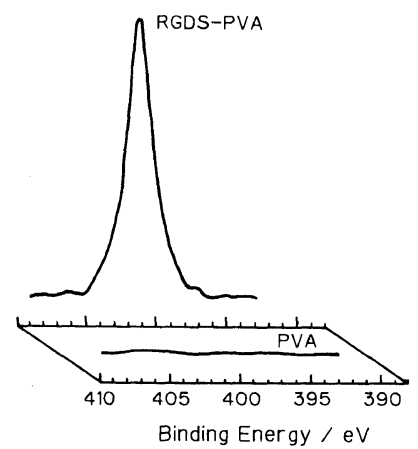

Figure 2. N1s ESCA spectra of PVA and RGDS-PVA surfaces.
35.06 mean that about $70 \%$ of the $\mathrm{OH}$ residues locates on the surface and other residues are buried in the film interior. For PEA, the $\mathrm{O} / \mathrm{C}$

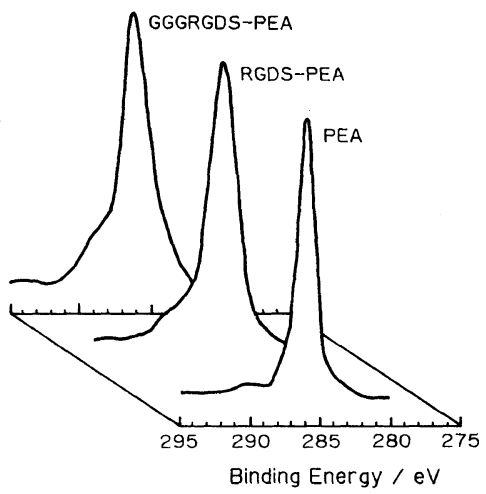

Figure 3. C1s ESCA spectra of PEA, RDGS-PEA, and GGGRGDS-PEA surfaces.

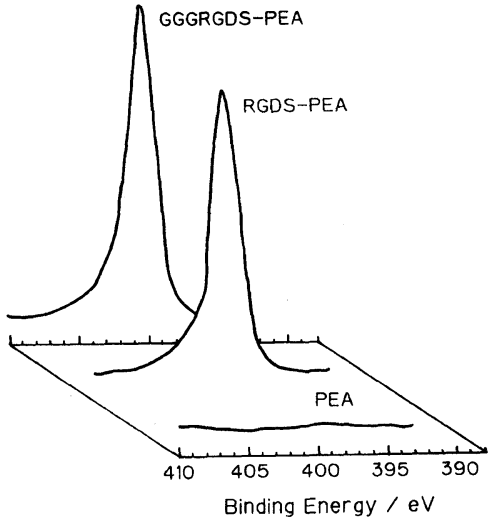

Figure 4. N1s ESCA spectra of PEA, RGDS-PEA, and GGGRGDS-PEA sirfaces.

Table I. Surface composition and critical surface tension

\begin{tabular}{|c|c|c|c|}
\hline \multirow{2}{*}{ Designation } & \multicolumn{2}{|c|}{ Elemental ratios } & \multirow{2}{*}{$\begin{array}{c}\begin{array}{c}\text { Critical } \\
\text { surface } \\
\text { tension }\end{array} \\
\gamma_{\mathrm{c}} / \text { dyn cm }^{-1}\end{array}$} \\
\hline & $\mathrm{O}: \mathrm{C} / \%$ & $\mathrm{~N}: \mathrm{C} / \%$ & \\
\hline PVA & 35.21 & 0 & 39.05 \\
\hline RGDS-PVA & 35.92 & 10.28 & 41.09 \\
\hline PEA & 2.12 & 0 & 35.15 \\
\hline RGDS-PEA & 12.03 & 5.35 & 37.31 \\
\hline $\begin{array}{l}\text { GGGRGDS- } \\
\text { PEA }\end{array}$ & 13.99 & 5.60 & 38.58 \\
\hline
\end{tabular}


$\%$ of bulk PEA is $3.7 \%$, so, about $57 \%$ of the $\mathrm{COOH}$ residues locate on the surface. Distributions of hydrophilic residues such as $\mathrm{OH}$ and $\mathrm{COOH}$ on the film surface are strongly dependent on the procedure to prepare films. Obvionsly from the figures, $\mathrm{C} 1 \mathrm{~s}$ peak of the oligopeptide-immobilized films exhibits a shoulder at $289-291 \mathrm{eV}$ characteristics to carbon atom of the amide bond, and N1s peaks of immobilized films are remarkable, in contrast to the absence of peak for PVA and PEA. Thus, we confirmed that the oligopeptides were really immobilized to substrate polymer films. The critical surface tension $\gamma_{c}$ (=39.05 dyn $\mathrm{cm}^{-1}$ ) of PVA is quite large. $\gamma_{c}$ $\left(=35.15 \mathrm{dyn} \mathrm{cm}^{-1}\right)$ of PEA, whose acrylic acid content is $2.84 \mathrm{~mol} \%$ is compared with $\gamma_{c}$ $(=31)$ of polyethylene. ${ }^{6}$ The critical surface tensions of oligopeptide-immobilized polymers, RGDS-PVA, RGDS-PEA, and GGGRGDS-PEA, are larger than those of respective substrate polymers, PVA and PEA. This fact means that the hydrophilicity of the surface is increased by immobilizing oligopeptides carrying polar amino acid residues such as Arg, Asp, and Ser.

\section{Adsorption Behaviors of $B S A$ and $\operatorname{IgG}$ on Oligopeptide-Immobilized PVA and PEA}

In Figure 5, the interfacial tension $\gamma_{\mathrm{HW}}^{\prime}$ between $n$-hexane and protein solution (Protein-PBS) is plotted against time. The interfacial tension $\gamma_{\mathrm{HW}}$ between $n$-hexane and PBS was $49.9 \mathrm{dyn} \mathrm{cm}^{-1}$ independent of time, though not shown in the figure. The reason why $n$-hexane was used is that the interfacial tension ( $51.0 \mathrm{dyn}^{-1}$ ) of $n$-hexane against water is the largest among various organic liquids. $\gamma_{\mathrm{HW}}=49.9 \mathrm{dyn}^{-1}$ obtained for PBS was slightly lower than the value for water. As shown in the figure, $\gamma_{\mathrm{HW}}^{\prime}$ for both BSA and IgG decreases with time, and approaches to an equilibrium value after about $3 \mathrm{~h}$. The curve for IgG is on higher level than for BSA. This means that protein molecules are adsorbed at the interface with time, and reduce the

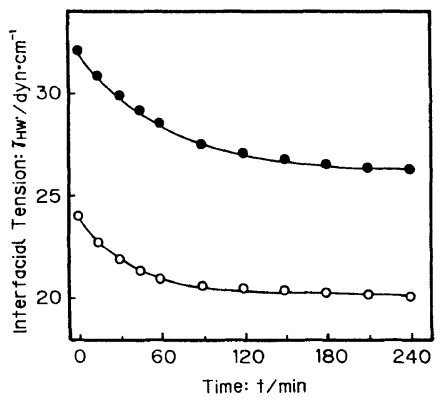

Figure 5. Time dependence of interfacial tentions $\gamma_{\mathrm{HW}}^{\prime}$ at $n$-hexane/protein solution interface for $0.1 \mathrm{wt} \% \mathrm{BSA}$ $(\mathrm{O})$, and $0.1 \mathrm{wt} \% \operatorname{IgG}(\bigcirc)$

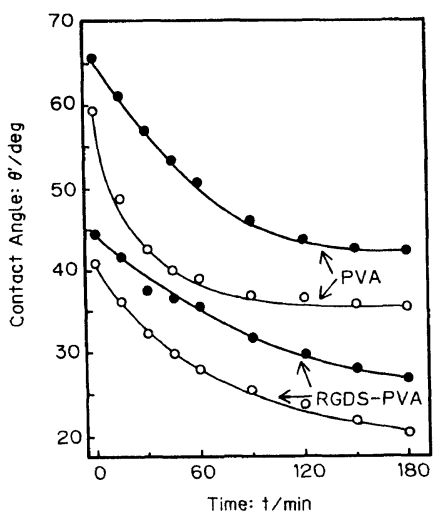

Figure 6. Contact angles of $0.1 \mathrm{wt} \% \mathrm{BSA}$ solution $(\mathrm{O})$, and $0.1 \mathrm{wt} \% \mathrm{IgG}$ solution (O) on PVA and RGDS-PVA surfaces plotted against time.

interfacial tension; mutual miscibility of $\operatorname{IgG}$ solution with $n$-hexane is smaller than that for BSA solution. In IgG molecule, hydrophilic domain $\left(F_{\mathrm{ab}}\right)$ and hydrophobic domain $\left(F_{\mathrm{c}}\right)$ are localized, thus the $F_{\mathrm{c}}$ portion may orient toward $n$-hexane phase at the interface. The contact angles $\theta$ of PBS solution in the absence of proteins were $58.7^{\circ}$ for PVA, $154.0^{\circ}$ for PEA, $18.9^{\circ}$ for RGDS-PVA, $118.0^{\circ}$ for RGDS-PEA, and $96.7^{\circ}$ for GGGRGDS-PEA, respectively, independent of time. The contact angles $\theta^{\prime}$ of $0.1 \%$ BSA solution and of $0.1 \% \mathrm{IgG}$ solution on PVA and RGDS-PVA films in $h$-hexane were plotted against time in Figure 6 . The curves indicate that equilibrium is attained after about $3 \mathrm{~h}$. The $\theta^{\prime}$ value for BSA solution is 


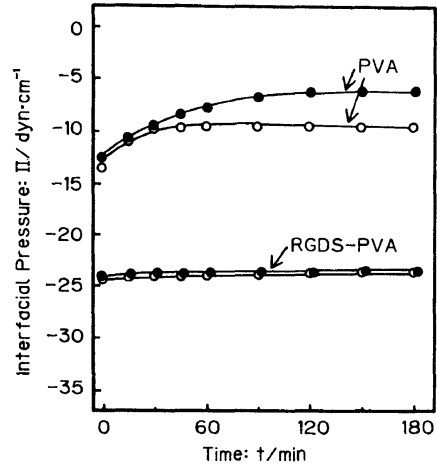

Figure 7. Time dependence of interfacial pressures of $0.1 \mathrm{wt} \%$ BSA solution $(O)$, and $0.1 \mathrm{wt} \%$ IgG solution on PVA and RGDS-PVA surfaces.

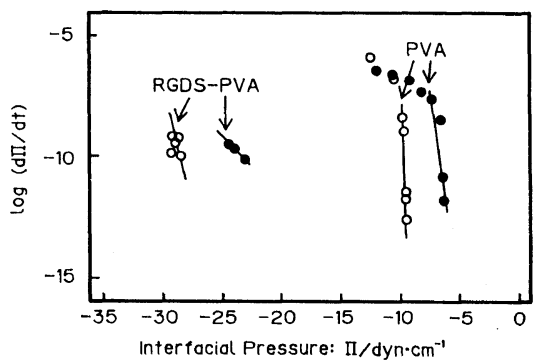

Figure 8. $\log (\mathrm{d} \Pi / \mathrm{d} t)$ plotted against $\Pi$ for adsorptions of $0.1 \mathrm{wt} \%$ BSA solution $(O)$ and $0.1 \mathrm{wt} \% \mathrm{IgG}$ solution (O) on PVA and RGDS-PVA surfaces.

higher than that for IgG solution owing to rather hydrophilic nature of BSA molecule. Introduction of RGDS peptide to PVA considerably reduces the contact angle for both BSA and IgG solution, because of the presence of polar groups in the peptide.

Figure 7 shows the interfacial pressure $\Pi$ obtained from eq 2. $\Pi$ indicates the extent of stabilization of interfacial energy between polymer film and protein solution. That is, a larger $\Pi$ value means that more stable interface is formed by the adsorption of protein molecules. It is pointed out that $\Pi$ is decreased by introducing RGDS to PVA. An important result shown in the figure is that the interfacial pressure is always minus. This fact indicates that surface of hydrophilic polymer, such as PVA, is difficult to adsorb the prtoein molecules BSA and IgG. In Figure $8, \log (\mathrm{d} \Pi / \mathrm{d} t)$

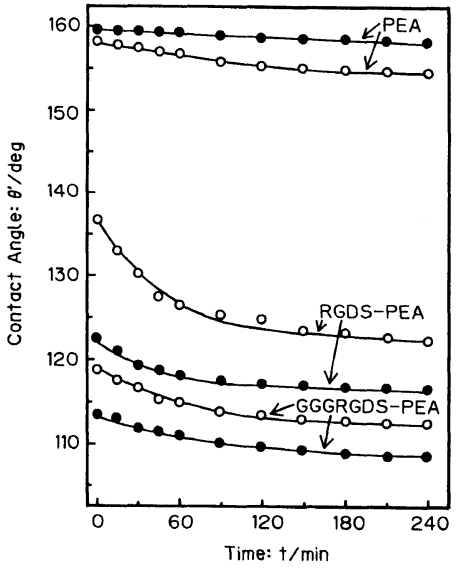

Figure 9. Contact angles of $0.1 \mathrm{wt} \% \mathrm{BSA}$ solution $(\mathrm{O})$, and $0.1 \mathrm{wt} \%$ IgG solution (O) on PEA, RGDS-PEA, and GGGRGDS-PEA surfaces plotted against time.

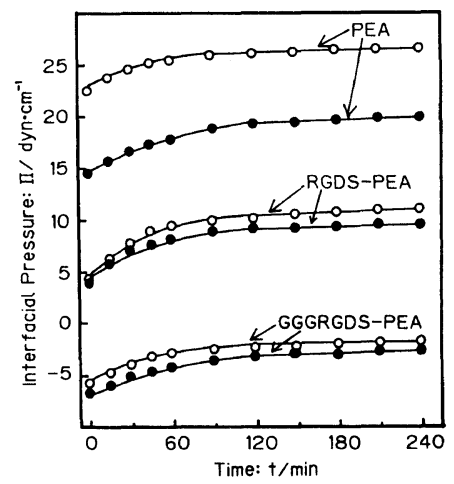

Figure 10. Time dependence of interfacial pressures of $0.1 \mathrm{wt} \%$ BSA solution $(O)$, and $0.1 \mathrm{wt} \%$ IgG solution $(O)$ on PEA, RGDS-PEA, and GGGRGDS-PVA surfaces.

is plotted against $\Pi$, from which the surface area $A$ of protein molecule is obtained from eq 1.

Next, experimental results on PEA, RGDSPEA, and GGGRGDS-PEA are given in Figures 9, 10, and 11. As mentioned before, PEA polymer is a copolymer of ethylene-acrylic acid, containing only $2.84 \mathrm{~mol} \%$ acrylic acid. So, PEA is said to be rather hydrophobic polymer: contact angle $\theta^{\prime}$ of PEA is considerably higher than that of PVA (Figure 6), and interfacial pressure $\Pi$ of PEA is positive (Figure 10). These values were, however, 


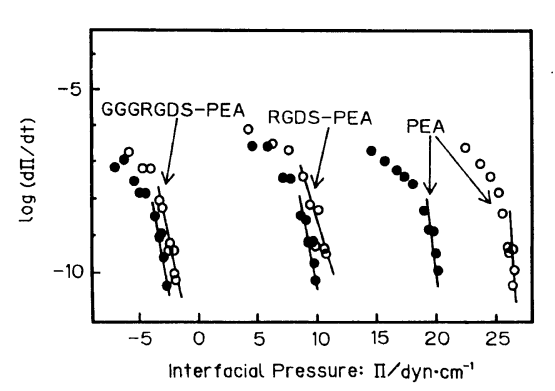

Figure 11. $\log (\mathrm{d} \Pi / \mathrm{d} t)$ plotted against $\Pi$ for adsorptions of $0.1 \mathrm{wt} \%$ BSA solution $(O)$ and $0.1 \mathrm{wt} \%$ IgG solution (๑) on PEA, RGDS-PEA, and GGGRGDS-PEA surfaces.

Table II. Surface pressure $\Pi$ and surface area $A$ of BSA and IgG on peptide-immobilized PVA and PEA surfaces

\begin{tabular}{|c|c|c|c|c|}
\hline \multirow{2}{*}{ Designation } & \multicolumn{2}{|c|}{$\Pi / \mathrm{dyn} / \mathrm{cm}^{-1}$} & \multicolumn{2}{|c|}{$A / \AA$} \\
\hline & BSA & IgG & BSA & IgG \\
\hline PVA & -9.4 & -6.3 & 980 & 1070 \\
\hline PGDS-PVA & -23.5 & -23.7 & 410 & 500 \\
\hline PEA & 26.7 & 20.3 & 940 & 630 \\
\hline PGDS-PEA & 11.1 & 10.0 & 510 & 460 \\
\hline $\begin{array}{l}\text { GGGRGDS- } \\
\text { PEA }\end{array}$ & -1.9 & -2.6 & 580 & 430 \\
\hline
\end{tabular}

drastically lowered by immobilization of RGDS and GGGRGDS.

Finally, $\Pi$ values at $3 \mathrm{~h}$, and $A$ values are summarized in Table II. As obvious from the table, for hydrophilic PVA surface, adsorption of BSA and IgG is not easy, and this tendency is increased by introducing RGDS peptide to PVA. For rather hydrophobic PEA surface, $\Pi$ (26.7, $20.3 \mathrm{dyn}^{-1}$ ) are positive values and not so large. But these are small positive values for RGDS-PEA, and finally suppressed to minus values for GGGRGDS-PEA. The effect of spacer, GGG, is distinguishable. Regarding the surface area, it is difficult to draw explicit explanation, but it seems that the surface areas are reduced by the immobilization of peptides to polymer surfaces. Dimensions of $A$ shown in the table are not largely conflict with those estimated from molecular dimensions of albumin and $\gamma$-globulin.

As mentioned earlier, this work was designed to elucidate the effects of serum proteins during cell attachment to peptide-immobilized polymer surface. The interaction of cells with peptide exhibiting cell-adhesion activity would be very specific. The results obtained in this paper may suggest that serum proteins BSA and IgG do not largely affect the cellattachment to the peptides, especially by the use of rather hydrophilic polymer surface.

Acknowledgment. The authors wish to thank Mr. Kenji Hirotsu for his cooperation in the experiments. This work was supported by the Grant-in-Aid for Scientific Research on Priority Area (No. 62604018 to A.N.), the Ministry of Education, Science, and Culture of Japan.

\section{REFERENCES}

1. M. D. Pierschbacher, E. G. Hayman, and E. Ruoslahti, Proc. Natl. Acad. Sci. U.S.A., 80, 1224 (1983).

2. M. D. Pierschbacher and E. Ruoslahti, Nature, 309, 000 (1984).

3. Y. Hirano, Y. Kando, T. Hayashi, T. Terai, K. Goto, and A. Nakajima, J. Biomed. Mater. Res., sumbitted (1990).

4. A. Nakajima and Y. Hata, Polym. J., 19, 493 (1987).

5. To be submitted shortly in J. Biomed. Mater. Res.

6. W. A. Zisman, "Contact Angle, Wettability, and Adhesion,” R. M. Fowkes, Ed., ACS Series 43, 1964, Chapter 1, pp $1-51$. 